\title{
Contrasting Iran's air quality improvement during COVID-19 with other global cities
}

\author{
Mohsen Yazdani ${ }^{1,2} \cdot$ Zeynab Baboli $^{3} \cdot$ Heidar Maleki $^{1,2} \cdot$ Yaser Tahmasebi Birgani ${ }^{4,5} \cdot$ Maryam Zahiri $^{2} \cdot$ \\ Seyede Saba Heydari Chaharmahal ${ }^{2} \cdot$ Mahdis Goudarzi $^{2} \cdot$ Mohammad Javad Mohammadi $^{1,4,5} \cdot$ Khan Alam $^{6}$. \\ Armin Sorooshian $^{7,8} \cdot$ Gholamreza Goudarzi ${ }^{1,4,5}$ (1)
}

Received: 15 February 2021 / Accepted: 25 August 2021 / Published online: 3 September 2021

(C) Springer Nature Switzerland AG 2021

\begin{abstract}
Background and purpose In late 2019, a novel infectious disease (COVID-19) was identified in Wuhan China, which turned into a global pandemic. Countries all over the world have implemented some sort of lockdown to slow down its infection and mitigate it. This study investigated the impact of the COVID-19 pandemic on air quality during 1st January to 30th April 2020 compared to the same period in 2016-2019 in ten Iranian cities and four major cities in the world.

Methods In this study, the required data were collected from reliable sites. Then, using SPSS and Excel software, the data were analyzed in two intervals before and after the corona pandemic outbreak. The results are provided within tables and charts.

Results The current study showed the COVID-19 lockdown positively affected Iran's air quality. During the COVID-19 pandemic, the four-month mean air quality index (AQI) values in Tehran, Wuhan, Paris, and Rome were 76, 125, 55, and 60, respectively, which are $8 \%, 22 \%, 21 \%$, and $2 \%$ lower than those during the corresponding period $(83,160,70$, and 61$)$ from 2016 to 2019.

Conclusions Although the outbreak of coronavirus has imposed devastating impacts on economy and health, it can have positive effects on air quality, according to the results.
\end{abstract}

Keywords COVID-19 $\cdot$ Coronavirus $\cdot$ Air quality $\cdot$ Lockdown $\cdot$ AQI

Gholamreza Goudarzi

ghgoodarzi@ajums.ac.ir

1 Air Pollution and Respiratory Diseases Research Center, Ahvaz Jundishapur University of Medical Sciences, Ahvaz, Iran

2 Department of Environmental Health Engineering, School of Public Health, Student Research Committee, Ahvaz Jundishapur University of Medical Sciences, Ahvaz, Iran

3 Department of Environmental Health Engineering, Behbahan Faculty of Medical Sciences, Behbahan, Iran

4 Department of Environmental Health Engineering, Ahvaz Jundishapur University of Medical Sciences, Ahvaz, Iran

5 Environmental Technologies Research Center (ETRC), Ahvaz Jundishapur University of Medical Sciences, Ahvaz, Iran

6 Department of Physics, University of Peshawar, Peshawar 25120 , Pakistan

7 Department of Chemical and Environmental Engineering, University of Arizona, Tucson, AZ, USA

8 Department of Hydrology and Atmospheric Sciences, University of Arizona, Tucson, AZ, USA

\section{Introduction}

Millions of people have been affected by coronavirus disease 2019 resultant from severe acute respiratory syndrome coronavirus 2 (SARS-CoV-2) worldwide since its arrival in December 2019 in Wuhan, China [9]. Coronavirus quickly spreading all over China and to other countries was officially termed as coronavirus disease 2019 (COVID-19) by the World Health Organization (WHO) [13]. Within five months, the disease had affected more than 210 countries, becoming a global pandemic and bringing devastating consequences [23]. The disease may have symptoms including shortness of breath, and cough in addition to fever [8]. As of July 22, 2021 , there were $192,853,619$ confirmed cases and 4,142,788 deaths (https://www.worldometers.info/ coronavirus/). Lockdown measures were run all over the world for reducing the spread of SARS-CoV-2, with various timing and severity based on the start of the epidemiological crisis and the infections evolution. A unique opportunity is presented by shifts in human mobility patterns caused by the 
enforced confinement/ lockdown related to the COVID-19 pandemic to recognize the impacts of human existence on urban and background air quality. It also advances our comprehension on air pollution [18].

Iran has been one of the most affected countries, which raises the question as to what the impact has been on air quality as many cities such as Tehran are usually extremely polluted. By initiating the worldwide COVID-19 pandemic, reduction has been observed in air pollution in some parts of the world compared to the conditions before and within the COVID-19 crisis [14]. There has been a moderate to significant lowering of air pollution in most parts of the world including China, Italy, and California [2]. In addition to particulate pollutants, greenhouse gas emissions have also fallen across continents [11]. Regarding greenhouse gas emissions, 72 and $11 \%$ of the transport sector's greenhouse gas emissions are accounted for by driving and aviation, respectively [16]. A reduction in $\mathrm{NO}_{2}$ pollution was first apparent near Wuhan, but spread across the rest of the country, and eventually worldwide. In central China, $\mathrm{NO}_{2}$ emissions were reduced by as much as $30 \%$ [17]. $\mathrm{CO}_{2}$ emissions, another common tracer of air pollution [10], decreased by $25 \%$ in China and by $6 \%$ worldwide [6].

The Air Quality Index (AQI) is used by government agencies to communicate to the public how polluted the air currently is and provides warnings about short-term or long-term effects of air pollution on public health. The establishment of ambient air quality standards can provide a basis for and guarantee the management of ambient air quality in order to protect human health, maintain ecological environmental safety, and promote harmonious, sustainable development that protects people, society, and nature [25]. The aim of this study was to investigate the effect of COVID-19 lockdowns on the ambient air quality in Iran's largest cities, and contextualized by comparing their results to Wuhan, Rome, Madrid, and Paris.

\section{Materials and methods}

\section{Study area}

In order to achieve the purpose of this study, ten populated cities were selected in Iran in addition to four major cities outside Iran (Fig. 1; Table 1).

\section{AQI Data}

To describe the air pollution level in each Iranian city, we obtained AQI data for four first months (1st January to 30th April) 2016-2020 from the Iran National Air Quality
Monitoring System (http://aqms.doe.ir). Related information for cities outside Iran was collected from the World Air Quality Index project (https://waqi.info). According to the United States Environmental Protection Agency (US EPA), the AQI is based on the level of six atmospheric pollutants: sulfur dioxide $\left(\mathrm{SO}_{2}\right)$, nitrogen dioxide $\left(\mathrm{NO}_{2}\right)$, suspended particulates $\left(\mathrm{PM}_{2.5}, \mathrm{PM}_{10}\right)$, carbon monoxide $(\mathrm{CO})$, and ozone $\left(\mathrm{O}_{3}\right)$. Based on the concentrations of each pollutant, an Individual Air Quality Index (IAQI) score is assigned (Eq. 1), and the final AQI is the highest of these six scores (Eq. 2). A higher AQI signifies more atmospheric pollutants in air and a higher level of air pollutions [19, 20].

$I A Q I_{p}=\frac{I_{\text {high }}-I_{\text {low }}}{C_{\text {high }}-C_{\text {low }}}\left(C_{p}-C_{\text {low }}\right)+I_{\text {low }}$

$A Q I=\max \left(\mathrm{I}_{1}, \mathrm{I}_{2},, \mathrm{I}_{\mathrm{n}}\right)$

$\mathrm{IAQI}_{\mathrm{P}}$ : the air quality sub index for air pollutant $\mathrm{p}$.

$\mathrm{C}_{\mathrm{P}}$ : the concentration of pollutant $\mathrm{p}$.

$\mathrm{C}_{\text {low }}$ : the concentration breakpoint that is $\leq \mathrm{C}_{\mathrm{P}}$.

$\mathrm{C}_{\text {high }}$ : the concentration breakpoint that is $\geq \mathrm{C}_{\mathrm{P}}$.

$\mathrm{I}_{\text {low }}$ : the index breakpoint corresponding to $\mathrm{C}_{\text {low }}$.

$\mathrm{I}_{\text {high }}$ : the index breakpoint corresponding to $\mathrm{C}_{\text {high }}$.

AQI values vary from " 0 " to " 500 " and its magnitude is proportional to pollutant concentrations in ambient air; therefore, higher AQI values indicate more serious health implications. If the AQI is greater than " 100 ," then the air quality is becoming unhealthy for certain groups (Jassim \& Coskuner, 2017).

\section{Results and discussion}

In the present study, data over a 5-year period were analyzed. Table 2 presents the minimum, maximum, and average of AQI from Jan-Apr 2016-2019 and Jan-Apr 2020 in ten Iranian megacities. Statistically significant differences between the two periods are denoted by $\mathrm{p}$ values below 0.05 . In Tabriz, the minimum, maximum, and mean of AQI from Jan-Apr 2016-2019 were 41, 191, and 93 respectively. These values for the same period in 2020 were 21, 145, and 64 respectively. The AQI average during Covid-19 was $31 \%$ lower in comparison to 2016-2019, and this change was statistically significant $(\mathrm{P}<0.0001)$. In Ahvaz, one of the most polluted cities in Iran, the AQI maximum in Jan-Apr 20162019 was 216 , which is classified as "very unhealthy", but this value decreased to 165 in 2020 . Consequently, the AQI maximum changed from "very unhealthy" to "unhealthy". Furthermore, the mean AQIs in Jan-Apr 2016-2019 and 2020 were 111 and 95, respectively; therefore, there was a change from "unhealthy for sensitive groups" to "moderate". 


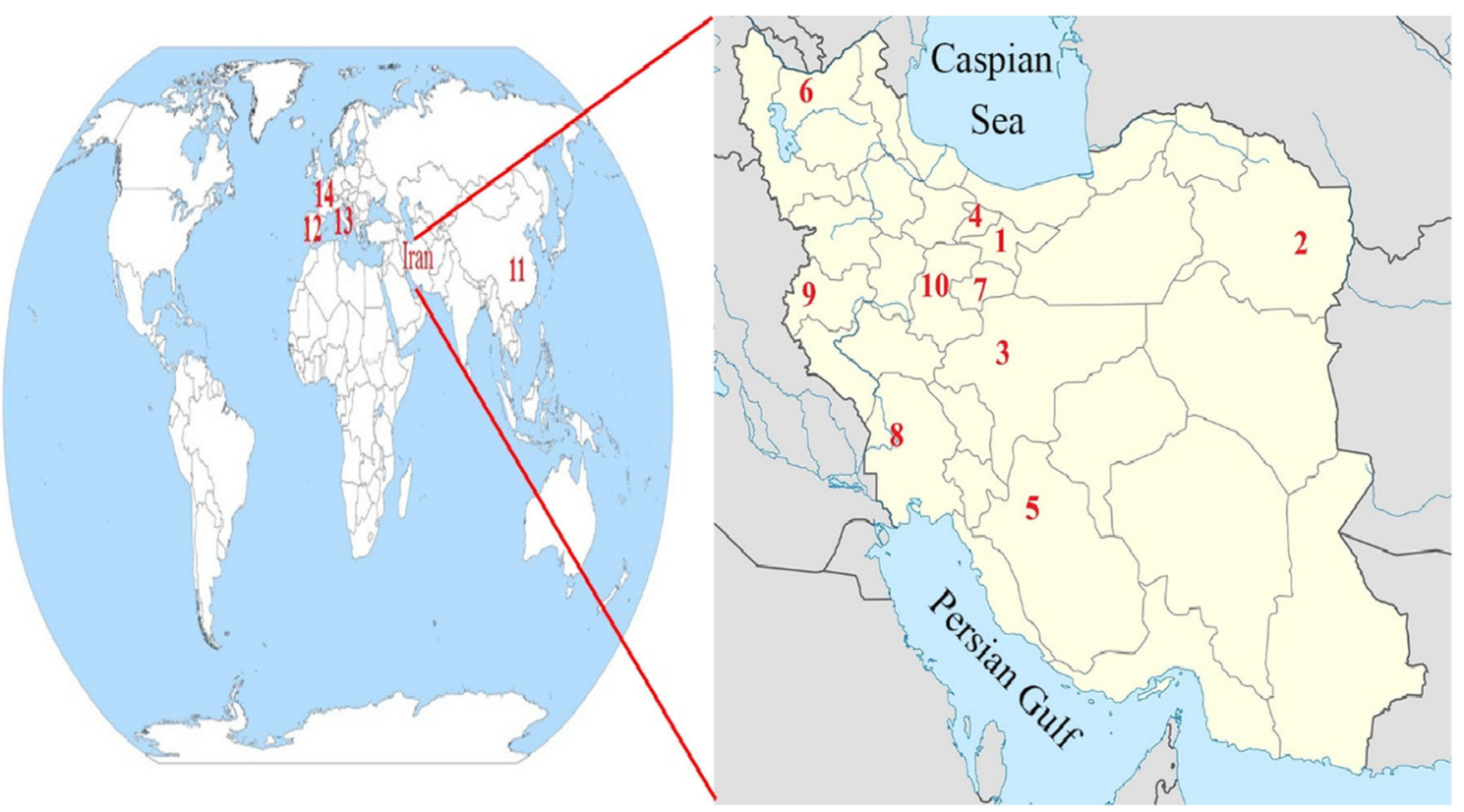

Fig. 1 Location of four cities (11; Wuhan, 12; Madrid, 13; Rome, 14; Paris) and Iranian megacities

In Tehran, the capital of Iran, the minimum and average AQI in Jan-Apr 2020 exhibited a 37 and $8 \%$ decrease in comparison to the same period in 2016-2019. In Kermanshah, mean of AQI in Jan-Apr 2016-2019 was in the "moderate" category, but during Covid-19 pandemic changed to being "good".

Figure 2 compares AQI averages between Jan-Apr 20162019 and Jan-Apr 2020 for the same ten Iranian cities. For example, the average AQI in Ahvaz in Jan-Apr 2020 was 95, which was $14.4 \%$ lower than that during the period from 2016-2019 (AQI = 111). The AQI in Shiraz was 69 in Jan-Apr 2020 and $15 \%$ lower than that during the period

Table 1 Populations and geographic coordinates of the studied megacities

\begin{tabular}{llrll}
\hline No. & City & Population & Longitude & \multicolumn{1}{l}{ latitude } \\
\hline 1 & Tehran & $8,693,706$ & $518,239 \mathrm{E}$ & $358,419 \mathrm{~N}$ \\
2 & Mashhad & $3,001,184$ & $598,369 \mathrm{E}$ & $368,169 \mathrm{~N}$ \\
3 & Isfahan & $1,961,260$ & $518,399 \mathrm{E}$ & $328,399 \mathrm{~N}$ \\
4 & Karaj & $1,592,492$ & $508,569 \mathrm{E}$ & $358,509 \mathrm{~N}$ \\
5 & Shiraz & $1,565,572$ & $528,349 \mathrm{E}$ & $298,369 \mathrm{~N}$ \\
6 & Tabriz & $1,558,693$ & $468,169 \mathrm{E}$ & $388,069 \mathrm{~N}$ \\
7 & Qom & $1,201,158$ & $508,529 \mathrm{E}$ & $348,389 \mathrm{~N}$ \\
8 & Ahvaz & $1,184,788$ & $488,409 \mathrm{E}$ & $318,199 \mathrm{~N}$ \\
9 & Kermanshah & 946,651 & $478,049 \mathrm{E}$ & $348,199 \mathrm{~N}$ \\
10 & Arak & 520,944 & $498,429 \mathrm{E}$ & $348,059 \mathrm{~N}$ \\
11 & Wuhan & $9,785,388$ & $1148179 \mathrm{E}$ & $308,359 \mathrm{~N}$ \\
12 & Madrid & $3,255,944$ & $38,429 \mathrm{~W}$ & $408,259 \mathrm{~N}$ \\
13 & Rome & $2,318,895$ & $128,299 \mathrm{E}$ & $418,549 \mathrm{~N}$ \\
14 & Paris & $2,138,551$ & $28,219 \mathrm{E}$ & $488,519 \mathrm{~N}$ \\
\hline
\end{tabular}

from 2016-2019 (AQI = 81). The AQI in Tabriz for Jan-Apr 2020 was 64, which was $31 \%$ lower than that during the period from 2016-2019 (AQI = 93). In Qom and Mashhad, the average AQIs showed a $2 \%$ and a $6 \%$ decrease during Covid-19 pandemic in comparison to Jan-Apr 20162019 ( $p=0.582$ and $p=0.013$ ). In Jan-Apr 2020, the AQI average in Arak decreased from 84 to $69(p=0.000)$ in the same period in 2016-2019. As shown in Fig. 2a, the highest and lowest changes in AQI were seen in Kermanshah (48 \%) and Isfahan $(-13 \%)$, respectively. Figure $2 b$ presents the four-month average distribution of AQI classes in ten cities in Iran. As expected, Ahvaz had the highest AQI before and after coronavirus pandemic.

The four-month average distribution of AQI classes in capital of Iran and cities outside Iran are illustrated in Fig. 3. In Tehran, the proportions of AQI classes I, II, III, IV, V, and VI were $0 \%, 77 \%, 23 \%, 0 \%, 0 \%$, and $0 \%$, respectively, during Jan-Apr 2016-2019. These same classes in Jan-Apr 2020 accounted for $13 \%, 72 \%, 14 \%, 1 \%, 0 \%$, and $0 \%$ of the total data points, respectively. Compared with the average AQI in Jan-Apr 2016-2019, the AQI Class I in Jan-Apr 2020 increased to $13 \%$; Class II decreased to $72 \%$; and Class III decreased to $14 \%$. In Jan-Apr 2016-2019, in Wuhan, the most polluted city in this study, there was no AQI classes I and II, but class II increased to $20 \%$ during COVID-19. On the other hand, "very unhealthy" and "unhealthy" categories showed a $4 \%$ and a $33 \%$ decrease, respectively, in Jan-Apr 2020. In Rome, the capital of Italy, class I increased from $15 \%$ in 2016-2019 to $36 \%$ in 2020. Furthermore, the "moderate" category showed a $34 \%$ decrease during COVID-19 in comparison to Jan-Apr 2016-2019. In Paris, the "good" category in Jan-Apr 2016-2019 was $8 \%$, but 
Table 2 Descriptive statistics of AQI from 2016 to 2019 and during COVID-19 in Iranian megacities

\begin{tabular}{|c|c|c|c|c|c|c|c|c|c|}
\hline \multirow[t]{2}{*}{ City } & \multicolumn{4}{|c|}{ Jan-Apr 2016-2019 } & \multicolumn{4}{|c|}{ Jan-Apr 2020} & \multirow[t]{2}{*}{ P-Value } \\
\hline & Min & Max & Mean & $\pm \mathrm{SD}$ & Min & Max & Mean & $\pm \mathrm{SD}$ & \\
\hline Tabriz & 41 & 191 & 93 & 45 & 21 & 145 & 64 & 24 & $\mathrm{P}<0.0001$ \\
\hline Isfahan & 40 & 153 & 75 & 24 & 50 & 153 & 85 & 23 & $\mathrm{P}=0.000$ \\
\hline Karaj & 36 & 121 & 77 & 16 & 13 & 146 & 68 & 25 & $\mathrm{P}=0.001$ \\
\hline Tehran & 51 & 131 & 83 & 17 & 32 & 150 & 76 & 23 & $\mathrm{P}=0.001$ \\
\hline Mashhad & 50 & 123 & 81 & 13 & 22 & 142 & 76 & 27 & $\mathrm{P}=0.013$ \\
\hline Ahvaz & 66 & 216 & 111 & 35 & 43 & 165 & 95 & 30 & $\mathrm{P}=0.000$ \\
\hline Shiraz & 41 & 122 & 81 & 18 & 29 & 180 & 69 & 22 & $\mathrm{P}=0.000$ \\
\hline Qom & 33 & 183 & 70 & 26 & 13 & 220 & 69 & 35 & $\mathrm{P}=0.582$ \\
\hline Kermanshah & 37 & 169 & 85 & 39 & 9 & 272 & 44 & 30 & $\mathrm{P}=0.000$ \\
\hline Arak & 49 & 183 & 84 & 26 & 25 & 147 & 69 & 26 & $\mathrm{P}=0.000$ \\
\hline
\end{tabular}

The $\mathrm{p}$ values represent the significance level of the difference between the mean AQIs between the two time periods increased to $49 \%$ in the same time in 2020. In Madrid, the capital of Spain, the proportions of classes I, II, III, IV, V, and
VI in Jan-Apr 2016-2019 were $62 \%, 38 \%, 0 \%, 0 \%, 0 \%$, and $0 \%$, respectively. Compared with the average AQI in

a

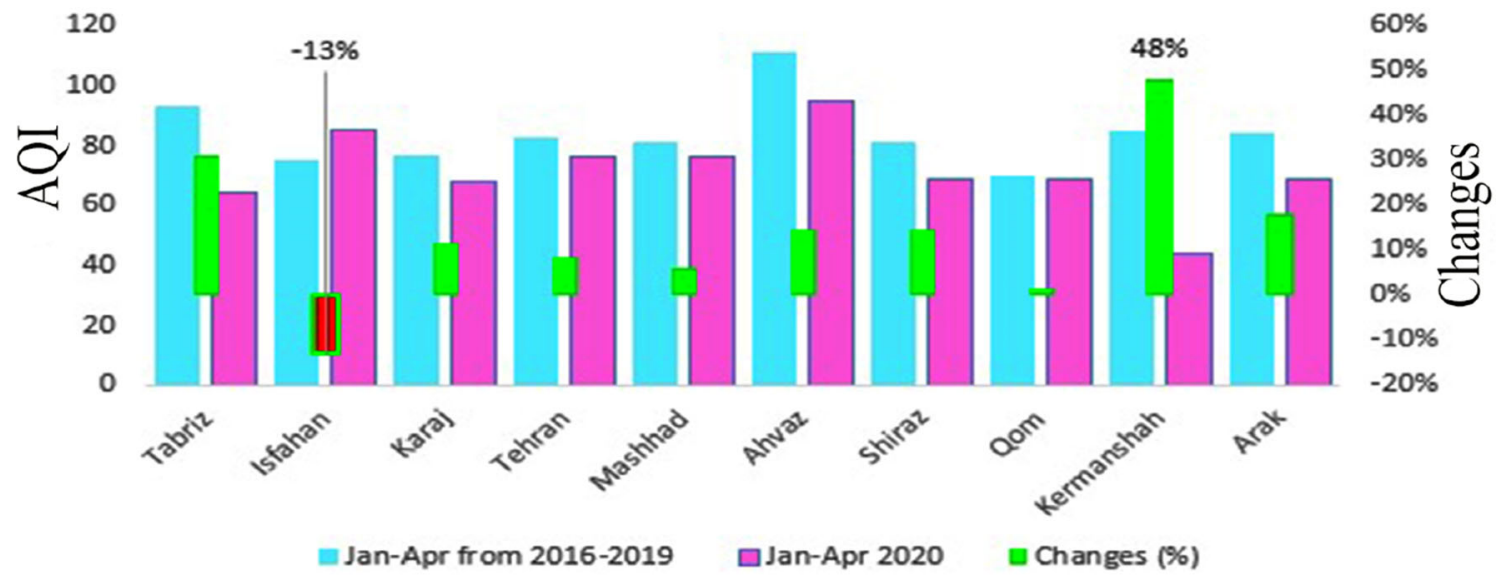

b

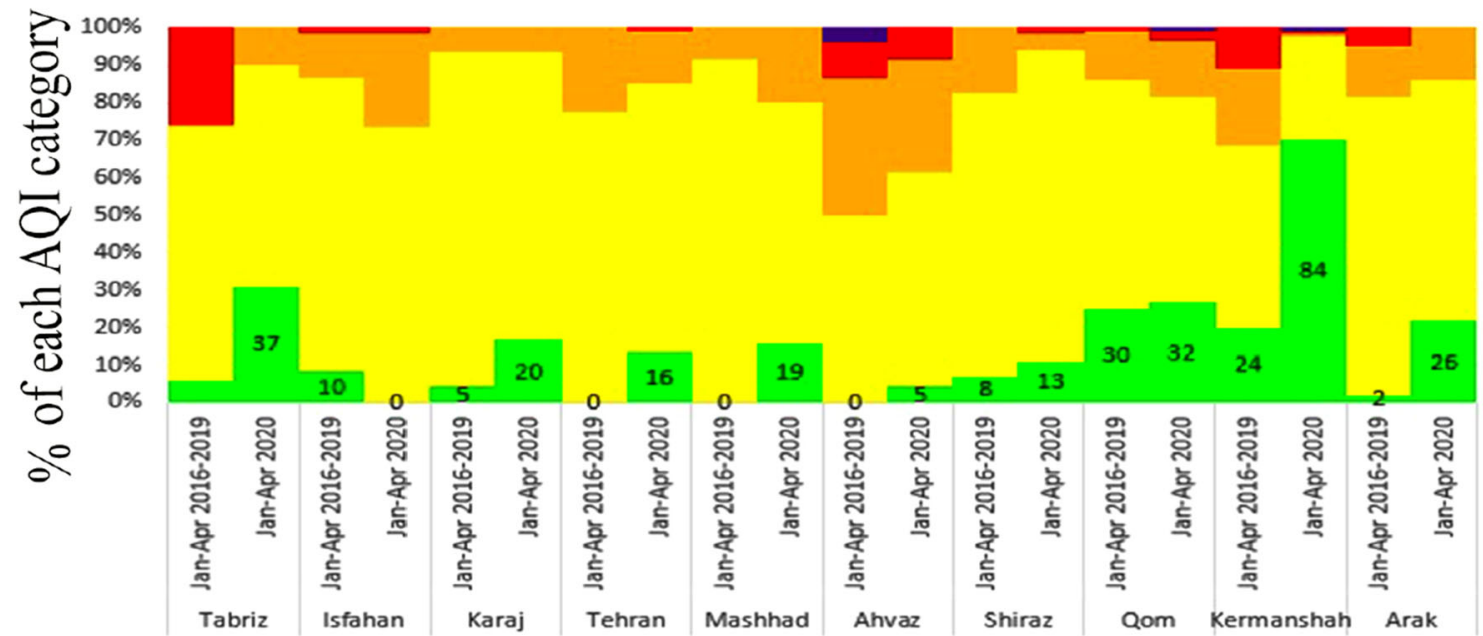

Fig. 2 Bar chart comparison of AQI averages in Iranian cities before and after the COVID-19 pandemic (a). Stacked column chart contrasting Iran's ambient air quality during the study period (b) 


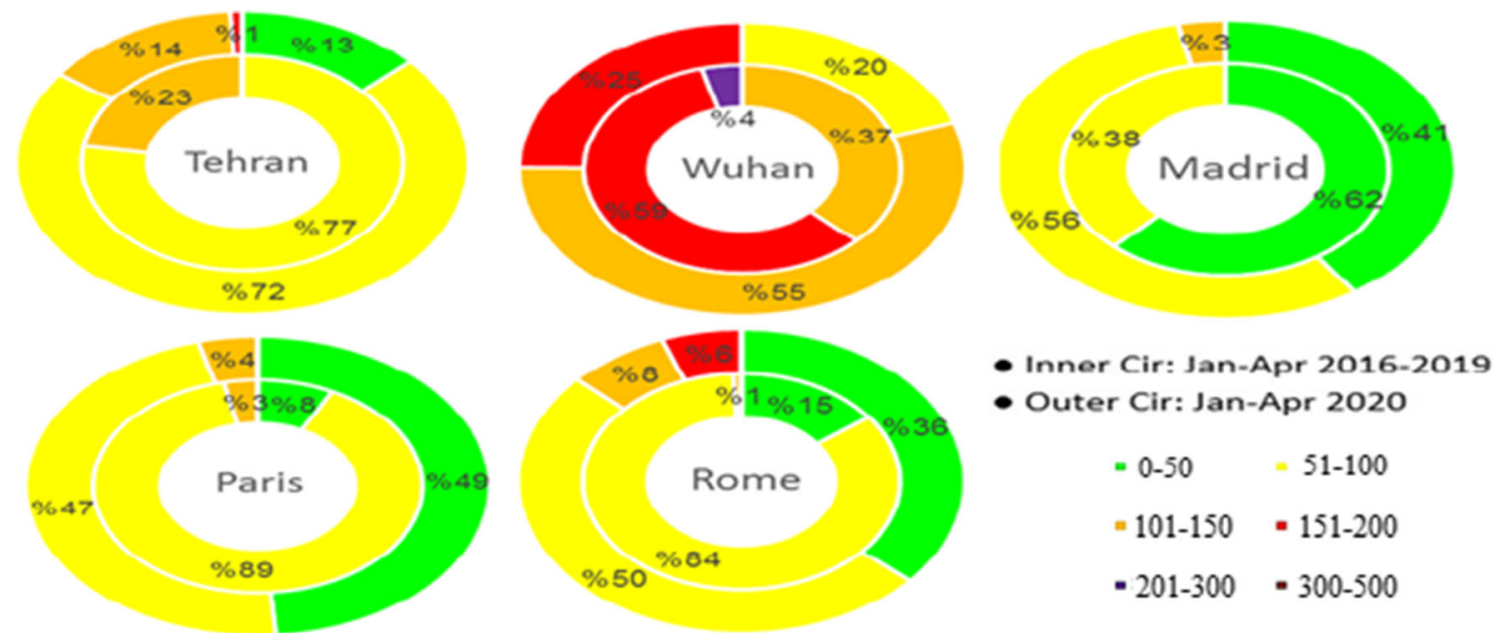

Fig. 3 Four-month average distribution of AQI before and after COVID-19 pandemic outbreak in Tehran and other global cities

Jan-Apr 2016-2019, AQI Class I in Jan-Apr 2020 decreased to $41 \%$, and AQI Class II increased to $56 \%$.

Figure 4 compares AQI averages between Jan-Apr 20162019 and Jan-Apr 2020 for Tehran and four major cities outside Iran. Tehran's AQI in Jan-Apr 2020 was 76, which was 8 $\%$ lower than that during the period from 2016 to 2019 (AQI = 83). The AQI in Wuhan in Jan-Apr 2020 was 125 , which was $22 \%$ lower than that during the period from 2016 to 2019 $(\mathrm{AQI}=160)$. Because the coronavirus was first detected in China, and resulted in a strict lockdown of Wuhan followed by mobility restrictions throughout the country, more studies focus on air pollution in China than other countries. Xu et al. [26], Wang and Su [24], Shi and Brasseur [21], Cole et al. [4], Fan et al. [7], and Almond et al. [1] all found that lockdowns and strict restrictions on economic activities in the city of Wuhan and other regions of China significantly reduced the level of major air pollutants. Shi and Brasseur [21] calculated that surface $\mathrm{PM}_{2.5}$ and $\mathrm{NO}_{2}$ levels decreased by 35 and $60 \%$, respectively, in northern China during the COVID-19 pandemic. Such a large short-term drop in air pollution is unprecedented in China, with only the strict regulations put in place

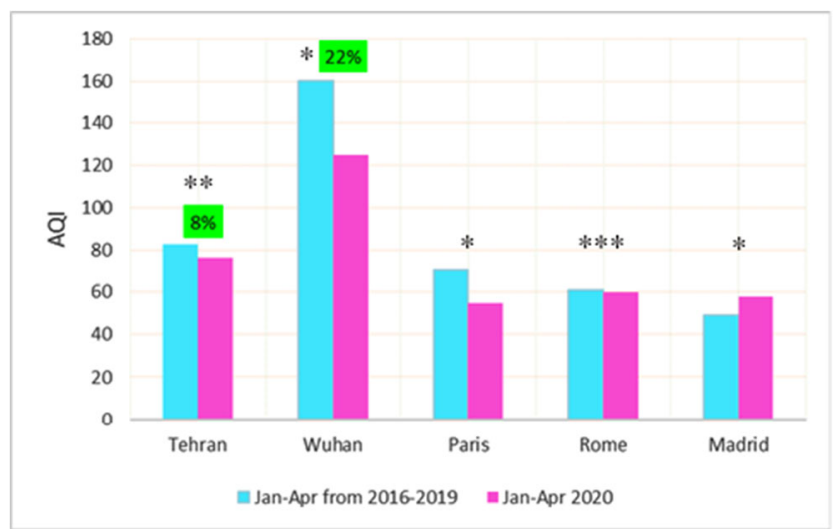

Fig. 4 Comparison of AQI averages in Tehran and cities outside Iran. *: $\mathrm{p}<0.0001, * *: \mathrm{p}=0.008, * * * \mathrm{p}=0.77$ during the 2008 Beijing Olympics producing comparable reductions [3]. However, most of these studies also found that $\mathrm{O}_{3}$ increased by as much as a factor of 2 due to reductions in nitrogen oxides. Studies of the effect of COVID-19 in China [7, 21], Milan, Italy [5], and Delhi, India [15] have also reported increases in $\mathrm{NO}_{2}$ and other pollutants with concomitant reductions in $\mathrm{O}_{3}[7,21]$. Ground-level $\mathrm{O}_{3}$ can be diminished by nitrogen oxides, so it is not uncommon to measure decreases in $\mathrm{O}_{3}$ when levels of $\mathrm{NO}_{2}$ rise [12, 21]. However, in some European cities where the sources of pollution are more varied such as from residential and commercial buildings, industrial activities, and road traffic, the changes are less apparent as such emissions could have continued despite lockdown [22].

\section{Conclusions}

During the COVID-19 outbreak, there was a dramatic decrease in human activities, resulting in significant reductions in pollutant levels in the atmosphere. In this study, we used AQI data to investigate the impact of the COVID-19 outbreak on air quality. We compared AQI mean values in January-April 2016-2019 with those from January-April 2020. The current study showed that the COVID-19 pandemic positively affected ambient air quality in Tehran, Mashhad, Ahvaz, Tabriz, Shiraz, Arak, Qom, Kermanshah, and Karaj, but Isfahan showed a reverse trend. Compared to Madrid, Paris, and Rome, Wuhan experienced the greatest reductions in AQI (22\%) in January-April 2020. The results demonstrate that it is possible to have significant air quality improvement by effective traffic control programs along with promoting green commuting and the technologies to expand remote working. Although the COVID-19 control measures restricted travel freedom and economic development and forced people 
to conduct many activities remotely, a benefit has been improvement in ambient air quality.

Acknowledgements We would like to thank the Ahvaz Jundishapur University of Medical Sciences (AJUMS) for the financial support of this grant project (APRD-0003).

\section{Declarations}

Conflict of interest The authors declare that they have no known conflict of interest, competing financial interests, or personal relationships that could have appeared to influence the work reported in this paper.

\section{References}

1 Almond D, Du X, Zhang S. Ambiguous pollution response to COVID-19 in China. Cambridge: National Bureau of Economic Research; 2020.

2 Anjum NA. Good in The Worst: COVID-19 Restrictions and Ease in Global Air Pollution; 2020. https://doi.org/10.20944/ preprints202004.0069.v1

3 Chang H-H, Meyerhoefer C, Yang F-A. COVID-19 prevention and air pollution in the absence of a lockdown. Cambridge: National Bureau of Economic Research; 2020.

4 Cole MA, Elliott RJ, Liu B. The impact of the Wuhan Covid-19 lockdown on air pollution and health: a machine learning and augmented synthetic control approach. Environ Resour Econ. 2020;76: 553-80.

5 Collivignarelli MC, Abbà A, Bertanza G, Pedrazzani R, Ricciardi P, Miino MC. Lockdown for CoViD-2019 in Milan: What are the effects on air quality? Sci Total Environ. 2020;732:139280.

6 Dutheil F, Baker JS, Navel V. COVID-19 as a factor influencing air pollution? Environ Pollut (Barking, Essex: 1987). 2020;263: 114466.

7 Fan C, Li Y, Guang J, Li Z, Elnashar A, Allam M, de Leeuw G. The impact of the control measures during the COVID-19 outbreak on air pollution in China. Remote Sens. 2020;12:1613.

8 Hadei M, Hopke PK, Jonidi A, Shahsavani A. A letter about the airborne transmission of SARS-CoV-2 based on the current evidence. Aerosol Air Qual Res. 2020;20:911-4.

9 Hadei M, et al. Presence of SARS-CoV-2 in the air of public places and transportation. Atmos Pollut Res. 2021;12:302-6.

10 Hanaoka T, Masui T. Exploring effective short-lived climate pollutant mitigation scenarios by considering synergies and trade-offs of combinations of air pollutant measures and low carbon measures towards the level of the 2C target in Asia Environ Pollut, 2020;261:113650.

11 Henriques M. Will Covid-19 have a lasting impact on the environment?. 2020. https://www.bbc.com/future/article/20200326-covid19-the-impact-of-coronavirus-on-the-environment. Accessed 14 May 2020
12 Jhun I, Coull BA, Zanobetti A, Koutrakis P. The impact of nitrogen oxides concentration decreases on ozone trends in the USA. Air Qual Atmos Health. 2015;8:283-92.

13 Baboli Z, Neisi N, Babaei AA, Ahmadi M, Sorooshian A, Tahmasebi Birgani Y, Goudarzi G (2021) On the airborne transmission of SARS-CoV-2 and relationship with indoor conditions at a hospital. Atmos Environ 261:118563.

14 Liu Q, et al. Spatiotemporal impacts of COVID-19 on air pollution in California. USA Sci Total Environ. 2021;750:141592.

15 Mahato S, Pal S, Ghosh KG. Effect of lockdown amid COVID-19 pandemic on air quality of the megacity Delhi, India. Sci Total Environ. 2020;730:139086. https://doi.org/10.1016/j.scitotenv. 2020.139086

16 Masson-Delmotte V, Zhai P, Pörtner HO, Roberts D, Skea J, Shukla PR, et al. "IPCC, 2018: summary for policymakers. In: global warming of $1.5^{\circ} \mathrm{C}$. An IPCC special report on the impacts of global warming of $1.5^{\circ} \mathrm{C}$ above pre-industrial levels and related global greenhouse gas emission pathways The Context of Strengthening the Global, Aromar Revi (2018). https://www.ipcc.ch/site/assets/ uploads/sites/2/2019/05/SR15_SPM_version_report_LR.pdf

17 NASA. Airborne nitrogen dioxide plummets over $\bar{C}$ hina. National Aeronautics and Space Administration. NASA: Earth Observatory. 2020. Available at: https://www.earth observatory.nasa.gov/images/ 146362/airbornenitrogendioxide-plummets-over-china

18 Querol X, et al. Lessons from the COVID-19 air pollution decrease in Spain: Now what? Sci Total Environ. 2021;779:146380.

19 She Q, et al. Air quality and its response to satellite-derived urban form in the Yangtze River Delta, China. Ecol Indic. 2017;75:297306.

20 Shen F, Ge X, Hu J, Nie D, Tian L, Chen M. Air pollution characteristics and health risks in Henan Province, China. Environ Res. 2017; 156:625-34.

21 Shi X, Brasseur GP. The response in air quality to the reduction of Chinese economic activities during the COVID-19 outbreak. Geophys Res Lett. 2020;47(11):e2020GL088,070. https://doi.org/ 10.1029/2020GL088070

22 Shrestha AM, Shrestha UB, Sharma R, Bhattarai S, Tran HNT, Rupakheti M. Lockdown caused by COVID-19 pandemic reduces air pollution in cities worldwide. 2020. https://doi.org/10.31223/osf. io/edt4j

23 Travaglio M, Yu Y, Popovic R, Selley L, Leal NS, Martins LM. Links between air pollution and COVID-19 in England. Environ Pollut. 2021;268:115859.

24 Wang Q, Su M. A preliminary assessment of the impact of COVID19 on environment - a case study of China. Sci Total Environ. 2020;728:38915. https://doi.org/10.1016/j.scitotenv.2020.138915

25. Xu K, Cui K, Young L-H, Wang YF, Hsieh YK, Wan S, Zhang J (2020) Air quality index, indicatory air pollutants and impact of COVID-19 event on the air quality near Central China. Aerosol Air Qual Res 20:1204-1221. https://doi.org/10.4209/aaqr.2020. 04.0139

26. Xu K, Cui K, Young L, Hsieh Y, Wang Y, Zhang J, Wan S. Impact of the COVID-19 event on air quality in Central China. Aerosol Air Qual Res. 2020;20:915-29.

Publisher's Note Springer Nature remains neutral with regard to jurisdictional claims in published maps and institutional affiliations. 